\title{
Dynamic analysis of planetary gear train system with double moduli and pressure angles
}

\author{
Heyun Bao, Guanghu Jin, Fengxia Lu, Rupeng Zhu, and Xiaozhu Zou \\ Nanjing University of Aeronautics and Astronautics, Nanjing 210016, China
}

\begin{abstract}
The planetary gear transmission with double moduli and pressure angles gearing is proposed for meeting the low weight and high reliability requires. A dynamic differential equation of the NGW planetary gear train system with double moduli and pressure angles is established. The 4-Order Runge-Kutta numerical integration method is used to solve the equations from which the result of the dynamic response is got. The dynamic load coefficients are formulated and are compared with those of the normal gear train. The double modulus planetary gear transmission is designed and manufactured. The experiment of operating and vibration are carried out and provides.
\end{abstract}

\section{Introduction}

Planetary gear train is widely used in the helicopters, automobiles, aircraft engines and ships. It has numerous advantages in size, weight, gear ratio, efficiency and load capacity. Many scholars have made a lot of researches on it. M. Inalpolat and A. Kahraman [1] proposed a simplified mathematical model of the planetary gear sets. A special experimental planetary gear set-up is developed and planetary gear sets from three of these five groups are procured. A nonlinear time-varying dynamic model is proposed to predict modulation sidebands of planetary gear sets [2]. Yichao Guo and Robert G. Parker [3] systematically study the mesh phase relations of general compound planetary gears. Experimental modal analysis techniques are applied to characterize the planar dynamic behavior of two spur planetary gears [4]. The highly structured modal properties of planetary gears having diametrically opposed planets and an elastic ring gear are illustrated and mathematically proved [5]. The dynamic responses of a planetary gear are analyzed when component gears have time-varying pressure angles and contact ratios caused by bearing deformations [6]. In [7] a dynamic differential equation of the NGW planetary gear train system with unequal moduli and pressure angles is established. In [8] the nonlinear dynamic model of one planetary gear transmission is set and the experiment is carried out. A nonlinear lateral-torsional coupled vibration model of a planetary gear system was established by taking transmission errors, time varying meshing stiffness and multiple gear backlashes into account [9]. In this paper, a dynamic differential equation of the NGW planetary gear train system with double moduli and pressure angles gearing is established. The 4-Order Runge-Kutta numerical integration method is used to solve the equations from 
which the result of the dynamic response is got. The dynamic load coefficients are formulated and are compared with those of the normal gear train. The planetary gear transmission with double moduli and pressure angles gearing is designed and manufactured. In addition, the experiment is carried out.

\section{System parameters}

Fig.1 illustrates a single stage planetary gear train consisting of a sun gear, a ring gear, several planets and a carrier. Sun gear is selected as the input component and the carrier as the output component. There are two double moduli and pressure angles gearings in the planetary gear train. One is external gear pair $z_{\mathrm{s}}-\mathrm{Z}_{\mathrm{pi}}$, the parameters of which meet

$$
m_{s} \cos \alpha_{s}=m_{p i} \cos \alpha_{p i}
$$

Where, $m_{\mathrm{s}}$ and $m_{\mathrm{pi}}$ are moduli of sun and planet gears respectively; $\alpha_{\mathrm{s}}$ and $\alpha_{\mathrm{pi}}$ are pressure angles of sun and planet gears respectively. The other is internal gear pair $\mathrm{Z}_{\mathrm{pi}}-\mathrm{Z}_{\mathrm{r}}$, the parameters of which meet

$$
m_{p i} \cos \alpha_{p i}=m_{r} \cos \alpha_{r}
$$

Where, $m_{\mathrm{pi}}$ and $m_{\mathrm{r}}$ are moduli of planet and ring gears respectively; $\alpha_{\mathrm{pi}}$ and $\alpha_{\mathrm{r}}$ are pressure angles of planet and ring gears respectively.

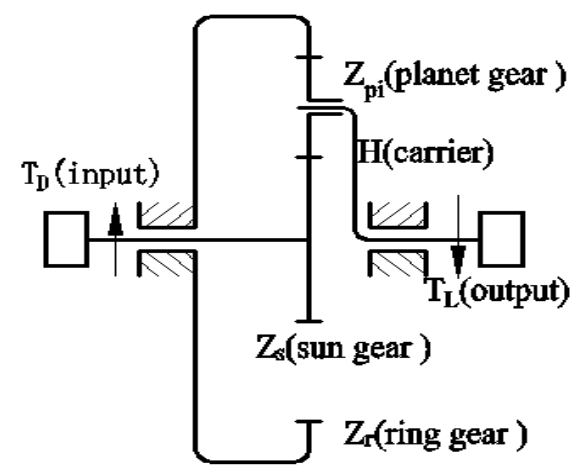

Fig. 1. Movement diagram.

\section{Dynamics model of planetary gear system}

The dynamic model of the system is shown in Fig.2. Planet carrier is the reference coordinate system of the model. The three degrees of freedom of sun gear are fixed on the planet carrier and the origin is coincident with the planet carrier center. The planet gear center is chosen as the origin of coordinate system and is fixed on the planet carrier, too. The system has $(6+3 N)$ degrees of freedom and the generalized coordinate $X$ can be expressed as follows:

$$
X=\left(x_{d}, x_{s}, H_{\mathrm{s}}, V_{\mathrm{s}}, H_{p i}, V_{p i}, x_{\mathrm{p} i}, x_{c}, x_{l}\right)^{T} \quad(i=1,2,3 \ldots \ldots . . N)
$$

where $H_{s}$ and $H_{p i}$ are the horizontal degrees of freedom of sun gear and planetary gear, respectively; $V_{s}$ and $V_{p i}$ are the vertical degrees of freedom of sun gear and planetary gear, respectively; $x_{d}$ and $x_{l}$ are the input and output component displacements, respectively; $x_{s}$, $x_{\mathrm{p} i}$ and $x_{c}$ are equivalent linear displacements on meshing line of sun gear, planet carrier and planetary gear, respectively; $N$ is the number of the planet gears. 


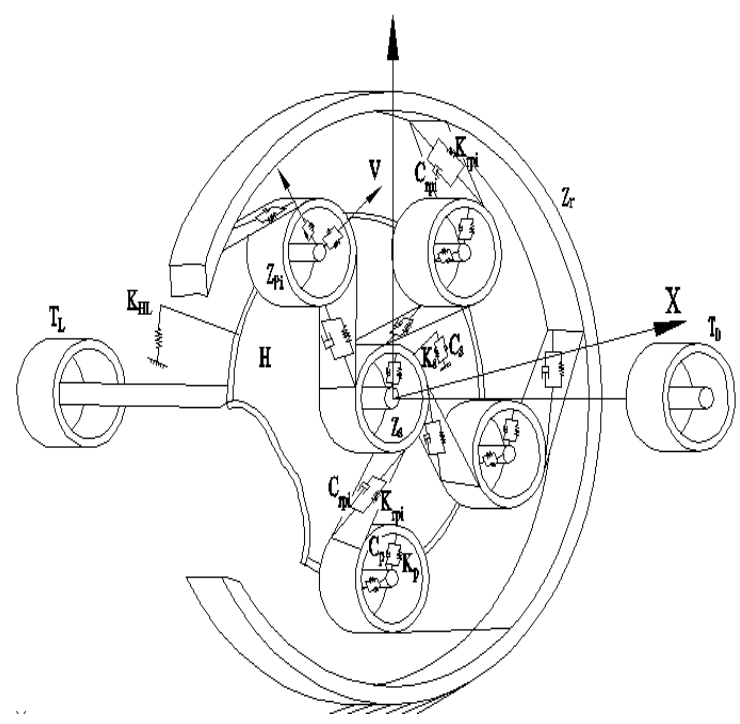

Fig. 2. Dynamics model of planetary gear system.

The equivalent accumulated meshing errors $e_{\mathrm{sp} i}$ of sun gear, planetary gear and internal gear eccentric error and displacement equivalent errors $e_{r p i}$ on the meshing line of each gear are as follows:

$$
\left\{\begin{array}{l}
e_{\mathrm{sp} i}(t)=E_{\mathrm{sp} i} \sin \left(\omega t+\phi_{\mathrm{sp} i}\right)+E_{\mathrm{s}} \sin \left(\omega_{\mathrm{sc}} t+\beta_{\mathrm{s}}-\phi_{i}\right)+E_{\mathrm{p} i} \sin \left(\omega_{\mathrm{pc}} t+\beta_{\mathrm{p} i}+\alpha\right) \\
e_{r \mathrm{p} i}(t)=E_{r \mathrm{p} i} \sin \left(\omega_{r} t+\phi_{r \mathrm{p} i}\right)-E_{\mathrm{p} i} \sin \left(\omega_{\mathrm{pc}} t+\beta_{\mathrm{s}}+\alpha\right)-E_{r} \sin \left(\omega_{r \mathrm{c}} t+\beta_{r}-\phi_{i}\right)
\end{array}\right.
$$

where $\varphi_{s p i}$ and $\varphi_{r p i}$ are initial phase of the teeth frequency errors $E_{s p i}$ and $E_{r p i}$ respectively; $E_{\mathrm{s}}$, $E_{\mathrm{pi}}$ and $E_{\mathrm{r}}$ are eccentric error of sun gear, planet gear and internal gear, the $\varphi_{s}, \varphi_{p i}$ and $\varphi_{r}$ are initial phase of those. $\omega$ is meshing frequency of epicyclic train; $\omega_{s c}, \omega_{p c}$ and $\omega_{r c}$ are angular velocity relative to planet carrier of sun gear, planetary gear and internal gear, respectively.

The relative displacement on the planetary gear transmission system line of action caused by rotation displacement are:

$$
\left\{\begin{array}{l}
x_{\mathrm{sp} i}=x_{\mathrm{s}}-x_{\mathrm{p} i}-x_{\mathrm{c}}-e_{\mathrm{sp} i}(t) \\
x_{r \mathrm{p} i}=x_{\mathrm{p} i}-x_{\mathrm{c}}-e_{r \mathrm{p} i}(t)
\end{array}\right.
$$

The forces $F_{\mathrm{sp} i}$ between sun gear and planetary gear and the force $F_{r \mathrm{p} i}$ between planetary gear and internal gear are respectively

$$
\left\{\begin{array}{l}
F_{\mathrm{sp} i}=K_{\mathrm{sp} i}\left(x_{\mathrm{sp} i}+\delta_{\mathrm{sp} i}-e_{\mathrm{sp} i}(t)\right) \\
F_{r \mathrm{p} i}=K_{r \mathrm{p} i}\left(x_{r \mathrm{p} i}-e_{r \mathrm{p} i}(t)\right)
\end{array} \quad(i=1,2, \ldots N)\right.
$$

The damping coefficient $C_{\mathrm{sp}}$ of sun gear with planetary gear is

$$
C_{\mathrm{sp}}=2 \zeta_{1} \sqrt{k_{\mathrm{sp}} /\left(1 / m_{\mathrm{p}}+1 / m_{\mathrm{s}}\right)}
$$

and the damping coefficient $C_{r \mathrm{p}}$ of planetary gear with internal gear is

$$
C_{r \mathrm{p}}=2 \zeta_{2} \sqrt{k_{r \mathrm{p}} /\left(1 / m_{r}+1 / m_{\mathrm{p}}\right)}
$$


where $\zeta_{1}$ and $\zeta_{2}$ are damping ratios of sun gear with planetary gear and planetary gear with internal gear; $k_{\mathrm{sp}}$ and $k_{r \mathrm{p}}$ are average action stiffnesses of sun gear with planetary gear and planetary gear with internal gear.

The damping force $D_{\mathrm{sp} i}$ of sun gear with planetary gear and $D_{r \mathrm{p} i}$ of planetary gear with internal gear respectively are

$$
\left\{\begin{array}{l}
D_{\mathrm{sp} i}=C_{\mathrm{sp} i}\left(\dot{x}_{\mathrm{sp} i}+\dot{\delta}_{\mathrm{sp} i}-\dot{e}_{\mathrm{sp} i}(t)\right) \\
D_{r p i}=C_{r \mathrm{p} i}\left(\dot{x}_{r \mathrm{p} i}-\dot{e}_{r \mathrm{p} i}(t)\right)
\end{array} \quad(i=1,2, \ldots N)\right.
$$

According dynamic model of planetary gear transmission system in Fig. 2, system dynamics equations are in the form:

$$
\left\{\begin{array}{l}
M_{\mathrm{d}} \ddot{x}_{\mathrm{d}}+\frac{K_{\mathrm{d}}}{\mathrm{r}_{\mathrm{bs}}^{2}}\left(x_{\mathrm{d}}-x_{\mathrm{s}}\right)=P_{d} \\
M_{\mathrm{s}} \ddot{x}_{\mathrm{s}}+\sum_{i=1}^{N}\left(F_{\mathrm{sp} i}+D_{\mathrm{sp} i}\right)-\frac{K_{\mathrm{d}}}{\mathrm{r}_{\mathrm{bs}}^{2}}\left(x_{\mathrm{d}}-x_{\mathrm{s}}\right)=0 \\
m_{\mathrm{s}} \ddot{H}_{\mathrm{s}}+\sum_{i=1}^{N}\left(F_{\mathrm{sp} i}+D_{\mathrm{sp} i}\right) \sin \left(\alpha_{\mathrm{sp}}-\varphi_{i}\right)+K_{\mathrm{s}} H_{\mathrm{s}}=0 \\
m_{\mathrm{s}} \ddot{V}_{\mathrm{s}}+\sum_{i=1}^{N}\left(F_{\mathrm{sp} i}+D_{\mathrm{sp} i}\right) \cos \left(\alpha_{\mathrm{sp}}-\varphi_{i}\right)+K_{\mathrm{s}} V_{\mathrm{s}}=0 \\
M_{\mathrm{p}} \ddot{x}_{\mathrm{p} i}-\left(F_{\mathrm{sp} i}+D_{\mathrm{sp} i}\right)+\left(F_{\mathrm{rp} i}+D_{\mathrm{rp} i}\right)=0 \\
m_{\mathrm{p}} \ddot{H}_{\mathrm{p} i}-\left(F_{\mathrm{sp} i}+D_{\mathrm{sp} i}\right) \sin \alpha_{\mathrm{sp}}+\left(F_{\mathrm{rp} i}+D_{\mathrm{rp} i}\right) \sin \alpha_{\mathrm{rp}}+K_{\mathrm{p}}\left[H_{\mathrm{p} i}-H_{\mathrm{c}} \cos \varphi_{i}-V_{\mathrm{c}} \sin \varphi_{i}\right]=0 \\
m_{\mathrm{p}} \ddot{V}_{\mathrm{p} i}-\left(F_{\mathrm{sp} i}+D_{\mathrm{sp} i}\right) \cos \alpha_{\mathrm{sp}}-\left(F_{\mathrm{rp} i}+D_{\mathrm{rp} i}\right) \cos \alpha_{\mathrm{rp}}+K_{\mathrm{p}}\left[V_{\mathrm{p} i}-x_{\mathrm{c}}+H_{\mathrm{c}} \sin \varphi_{i}-V_{\mathrm{c}} \cos \varphi_{i}\right]=0 \\
M_{\mathrm{c}} \ddot{x}_{\mathrm{c}}+K_{\mathrm{p}}\left(x_{\mathrm{c}}-\sum_{i=1}^{N} V_{\mathrm{p} i}\right)+\frac{K_{1}}{\mathrm{r}_{\mathrm{bc}}^{2}}\left(x_{\mathrm{c}}-x_{1}\right)=0 \\
M_{\mathrm{l}} \ddot{x}_{1}-\frac{K_{1}}{\mathrm{r}_{\mathrm{bc}}^{2}}\left(x_{\mathrm{c}}-x_{\mathrm{l}}\right)=-P_{l}
\end{array}\right.
$$

where, $\alpha$ is the pressure angle; $r_{\mathrm{b}}$ is the radius of gear base circle; $m_{s}, m_{p i}$ and $m_{c}$ are equivalent mass of the sun gear, planet gears and planet carrier, respectively, with $m_{k}=J_{k} / r_{k}^{2}$ $(k=s, p i, c) ; M_{d}, M_{s}, M_{p i}, M_{c}$ and $M_{l}$ are mass of the input component, sun gear, planet gears, planet carrier and load; $K_{\mathrm{s}}$ and $K_{\mathrm{p}}$ are support stiffness of sun gear and planet gears; $r_{c}$ is radius of base circle of planet carrier; $P_{d}$ and $P_{l}$ is the input and output force, respectively.

\section{Solution of dynamically differential equation}

The differential equations were solved by 4-Order Runge-Kutta method. The relevant parameters are as follow: $P=10 \mathrm{~kW}, n=1200 \mathrm{r} / \mathrm{min}, x_{s}=0.5417, x_{p i}=-0.416, x_{r}=0.2, z_{s}=30$, $z_{p i}=31, z_{r}=91, \alpha_{r}=24^{\circ}, m_{s}=m_{p i}=3.08 \mathrm{~mm}, m_{r}=3.12 \mathrm{~mm}, E_{\mathrm{s}}=3 \mu \mathrm{m}, E_{\mathrm{p} i}=3 \mu \mathrm{m}, E_{\mathrm{r}}=3 \mu \mathrm{m}$, $E_{\mathrm{sp} i}=3 \mu \mathrm{m}, \quad E_{\mathrm{rp} i}=3 \mu \mathrm{m}, \alpha_{s}=\alpha_{p i}=22.2698^{\circ}$.

The dynamic load coefficients of planetary gears are

$$
\left\{\begin{array}{l}
G_{s p i}=N\left(P_{s p i}\right)_{\max } / P_{d} \\
G_{r p i}=N\left(P_{r p i}\right)_{\max } / P_{l}
\end{array} \quad(i=1,2, \ldots N)\right.
$$

The time-domain graph of dynamic loads of the double moduli and the normal planetary gears $\left(\alpha=24^{\circ}, m=3.12 \mathrm{~mm}\right)$ were obtained as shown in Figs. 3-4. 


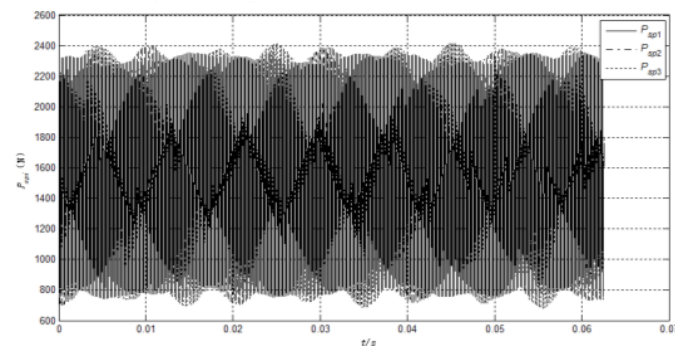

(a) The dynamic loads of the external gear pair

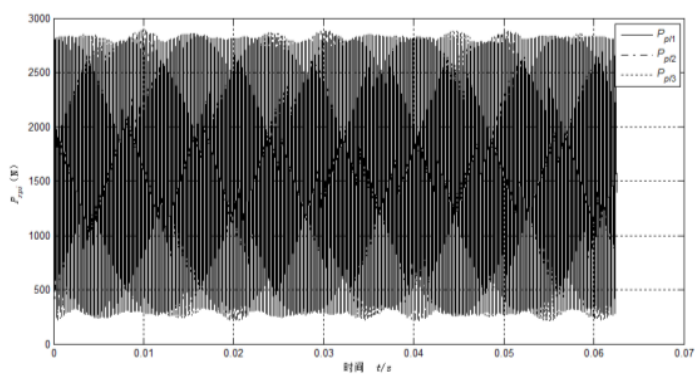

(b) The dynamic loads of the internal gear pair

Fig. 3. The dynamic loads of the double moduli planetary gears.

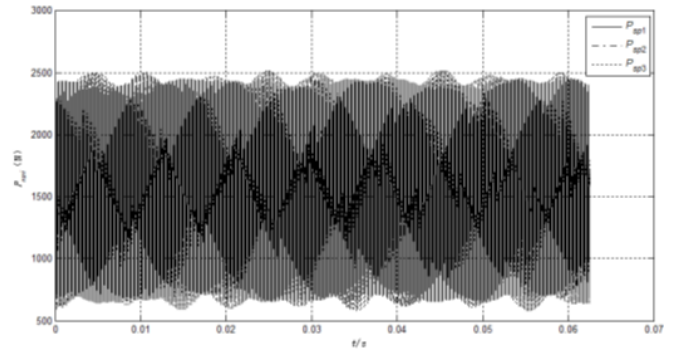

(a) The dynamic loads of the internal gear pair

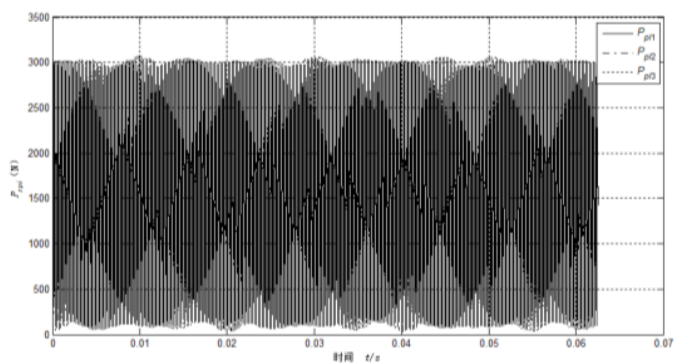

(b) The dynamic loads of the external gear pair

Fig. 4. The dynamic loads of the normal planetary gears.

The dynamic load coefficients of the double moduli and the normal planetary gears $\left(\alpha=24^{\circ}, m=3.12 \mathrm{~mm}\right)$ system were obtained as shown in Table 1 .

Table 1. The dynamic load coefficients of the double moduli and the normal one

\begin{tabular}{|c|c|c|c|c|c|c|}
\hline dynamic load coefficients & $G_{\mathrm{sp} 1}$ & $G_{\mathrm{sp} 2}$ & $G_{\mathrm{sp} 3}$ & $G_{\mathrm{rp} 1}$ & $G_{\mathrm{rp} 2}$ & $G_{\mathrm{rp} 3}$ \\
\hline double moduli planetary gears & 1.1950 & 1.2171 & 1.2265 & 1.2907 & 1.3053 & 1.3023 \\
\hline normal planetary gears & 1.2153 & 1.2371 & 1.2476 & 1.3206 & 1.3328 & 1.3284 \\
\hline
\end{tabular}

From Figs. 3-4 and Table 1, it is clear that the dynamic load and its coefficients of the double moduli planetary gears are smaller than those of the normal one. That means the dynamic behavior of the double moduli planetary gears is better than the normal one.

\section{Experimental verification}

The gear cutter for experimental double moduli planetary gears is shown in Fig. 5. Gear cutter hob is used to cut the sun gear and the planet gear and the gear shaper cutter for the ring gear.

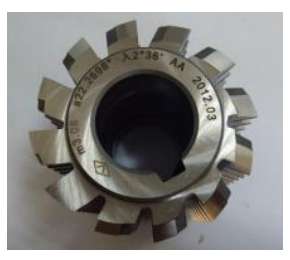

(a)Gear cutter hob $(m=3.08 \mathrm{~mm})$

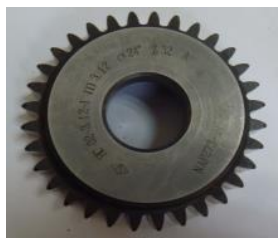

(b)Gear shaper cutter $(m=3.12 \mathrm{~mm})$

Fig. 5. Gear cutter for experimental double moduli planetary gears. 
Figure 6 shows the schematic of the test rig.

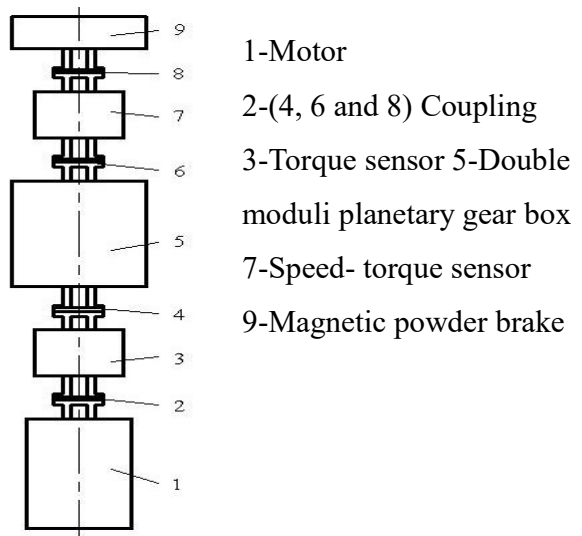

Fig. 6. The test rig schematic.

Test gears with strain gauges are shown in Fig. 7. In Fig. 7(a) is the sun gear with strain gauges and in Fig. 7(b) the ring gear with strain gauges.

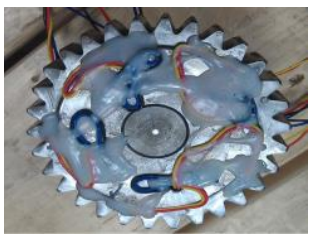

(a) sun gear

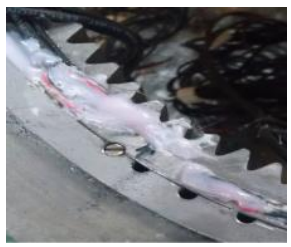

(b) ring gear

Fig.7. Test gears with strain gauges

Fig. 8 shows the experimental test system of the double moduli planetary gears and the corresponding results are shown in Fig. 9.

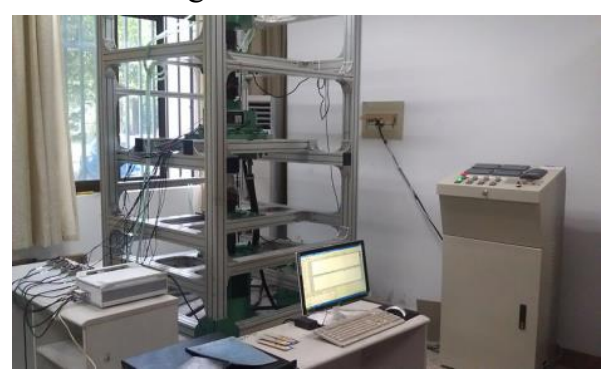

Fig. 8. Experimental test system of the double moduli planetary gears.

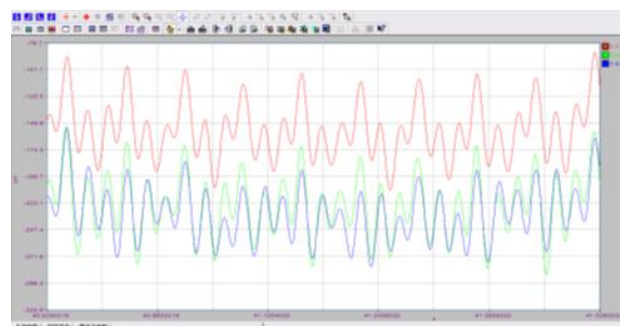

(a) The result test of the stress-strain curve

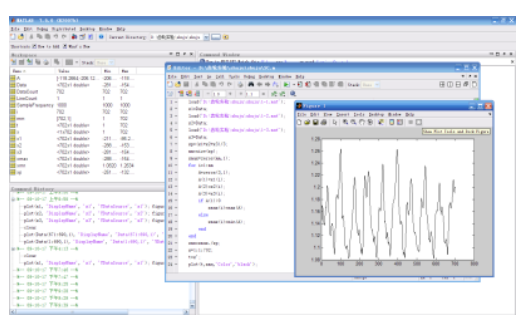

(b) The load-sharing coefficients of the test

Fig. 9. The result of the test. 
Table 2 shows the load-sharing coefficients of the test and the theoretical analysis and the errors between them.

Table 2. The load-sharing coefficients of the test and the theoretical analysis.

\begin{tabular}{|c|c|c|c|c|}
\hline Input Torque $(\mathrm{Nm})$ & 80 & 140 & 160 & 180 \\
\hline Test data & 1.26 & 1.29 & 1.22 & 1.18 \\
\hline Theoretical data & 1.21 & 1.21 & 1.14 & 1.12 \\
\hline error & $4.11 \%$ & $6.23 \%$ & $6.42 \%$ & $5.17 \%$ \\
\hline
\end{tabular}

\section{Conclusions}

A dynamic differential equation of the NGW planetary gear train system with double moduli and pressure angles gearing is established and solved. The dynamic load coefficients are formulated and compared with those of the normal gear train. The dynamic behavior of the planetary gear train with double moduli and pressure angles gearing is better than that of the normal one. The planetary gear transmission with double moduli and pressure angles gearing is designed and manufactured. The dynamic experiment of the double moduli planetary gears is carried. The dynamic loads, the dynamic load coefficients and the load-sharing coefficients of the test gear sets are obtained.

The project is supported by "the Fundamental Research Funds for the Central Universities", NO. NS2017031

\section{References}

[1] M. Inalpolat, A. Kahraman, Journal of Sound and Vibration 323, 677 - 696 (2009)

[2] M. Inalpolat, A. Kahraman, Journal of Sound and Vibration 329, 371 - 393 (2010)

[3] Y. Guo, R.G. Parker, Mechanism and Machine Theory 46, 1869 - 1887 (2011)

[4] T.M. Ericson, R.G. Parker, Journal of Sound and Vibration 332, 2350 - 2375 (2013)

[5] R.G. Parker, X. Wu, Journal of Sound and Vibration 329, 2265 - 2275 (2010)

[6] W. Kim, J.Y. Lee, J. Chung, Journal of Sound and Vibration 331, 883 - 901 (2012)

[7] F. Ye, R. Zhu, H. Bao, Journal of South China University of Technology 39, 118 - 123 (2011)

[8] F. Li, R. Zhu, H. Bao, C. Xiang, H. Liu, Journal of Nanjing University of Aeronautics \& Astronautics 44, 511 - 519 (2012)

[9] T. Li, R. Zhu, H. Bao, Cent. South Univ. 19, 1543-1547 (2012) 